\title{
Integrating Industry BIM Practices into University Curriculum
}

\section{Prof. Kevin R. Miller, Brigham Young University}

Kevin R. Miller Ph.D. is the Chair of the Construction Management Program at Brigham Young University. He has worked as an estimator for several companies in industry. His area of research focuses on Construction Modeling and Estimating. Kevin has also taught at Arizona State University and the University of Florida.

\section{Dr. Clifton B. Farnsworth, Brigham Young University}

Clifton Farnsworth received B.S. and M.S. degrees in civil engineering from Brigham Young University and a Ph.D. in civil engineering from the University of Utah. He worked as a geotechnical engineer for eight years with the Utah Department of Transportation, spent three years as an Assistant Professor of civil engineering at the University of Texas, Tyler, and has a current appointment as an Assistant Professor of construction management at Brigham Young University.

\section{Dr. Justin Earl Weidman, Brigham Young University}

Justin Weidman received his BS and MS degrees in Construction Management from Brigham Young University and a PhD from Virginia Polytechnic and State University in Environmental Design and Planning Justin worked as a project engineer and project manager in the construction industry for 3 years. And has a current appointment as a assistant professor at Brigham Young University. 


\section{Integrating Industry BIM Practices into University Curriculum}

\section{Introduction}

The use of Building Information Modeling (BIM) is becoming more prevalent in the engineering and construction community for both design and construction. ${ }^{1}$ Similarly, BIM is being integrated into university Construction Engineering and Management (CEM) curriculum, but unfortunately at a rate that is lagging the industry. ${ }^{2}$ While Brigham Young University has been incorporating BIM into the Construction Management (CM) curriculum for several years, we wanted to better understand how BIM was being implemented within industry practice in order to strengthen how BIM was being taught in the classroom.

During the summer of 2012, the lead author visited five different commercial construction companies (including nine different offices) and multiple projects across the United States that had implemented BIM to various extents. These companies were current leaders in BIM use within the construction industry. The purpose of the visits was to discover how companies were implementing BIM within their companies, both in preconstruction services and field operations, and then bring back to the classroom the best practices from these observations. In addition to visiting the offices of these companies, the following project types were also visited and observed for how BIM was being implemented: a 4 story office building addition, a cancer hospital, a university library remodel/expansion, a pharmaceutical lab, a new university library, a hospital expansion, a subway terminal expansion, a university hockey arena, a hotel, a university research animal facility, and a university dormitory project.

Gaining a better understanding of BIM use within the industry provided the framework for determining the implications of BIM across our entire construction management curriculum. This in turn has allowed us to provide our students with the latest industry best practices, strengthen their ability to contribute to the BIM efforts of the company upon graduation, and ultimately provide leadership to those companies adopting BIM. This paper is a summary of what was learned from these visits and the corresponding changes that we have made within the construction management curriculum at Brigham Young University.

\section{BIM Incorporation into CEM Curriculum}

There are many reasons that students should be exposed to BIM during their undergraduate education in the CEM disciplines, most notably because the construction industry continues to expand their use of BIM. However, there are also added benefits to the overall quality of the student's education that result from teaching BIM. A BIM based teaching approach has the potential to help CEM students effectively learn construction details and strengthen their understanding of the underlying concepts behind performing material quantity take-offs. ${ }^{3}$ In addition to better understanding the relationship between complex building components, ${ }^{4}$ using BIM allows students to better visualize a number of other construction processes, such as safety, sequencing, and operations. ${ }^{5}$

In recent years there have been many publications establishing the need for BIM integration into CEM curricula, how to do so effectively, and what skillset students need to obtain from those 
courses. Some programs have focused on general implementation of BIM across existing curriculum without adding specific BIM courses. ${ }^{6}$ This implementation includes integrating BIM within specific courses such as scheduling, ${ }^{7}$ estimating,,${ }^{8,9,10}$ engineering graphics, ${ }^{11}$ MEP (mechanical, electrical, and plumbing), ${ }^{12}$ or project management. ${ }^{13}$ Other programs are modifying their curriculum by adding specific stand-alone BIM courses. ${ }^{14,15}$ Cooksey and Schiff state that "introducing BIM to students is more complex than just adding a new course to the curriculum, because BIM has the potential to be involved in the entire program." ${ }^{16}$ However, they further clarify that integration of BIM within the curriculum should correspond with the student's academic maturity. ${ }^{16}$ While individual CEM programs have to balance how to best utilize BIM within their individual unique curriculum, it is clear that there is an increasing academic trend of programs incorporating BIM in an attempt to meet industry needs. ${ }^{17}$

Perhaps more important than simply "having BIM" incorporated within the curriculum is establishing what should be taught. Lee and Dosick report that the most important skills needed in the CEM field are the abilities to model detailed conditions in 3D, assemble and review a clash detection model, create 4D models using a schedule, and simply being able to utilize BIM software. ${ }^{18}$ Nejat, et. al. similarly report that the four most important skills identified by industry needs are clash detection and coordination, scheduling and 4D visualization, quality control, and quantification/estimation, in that order. ${ }^{19}$ Generally speaking, changes within academic curriculum should reflect industry needs. Management skills required of a BIM manager within the industry that can be developed within higher education include teamwork, communication, and analytical thinking. Technical skills include "understanding BIM tools, standards, workflows, BIM-enabled coordination practices and project management, development of construction drawings, making estimates and schedules with BIM applications, and a knowledge of parametric object-based design concepts. ${ }^{20}$ Both management and technical related skills should be integrated into BIM curriculum. According to the AIA, "the level of expertise required to intelligently design with BIM is significant, and serious consideration must be given to how it can be taught... The competent BIM operator must have an understanding of the tool, a sound knowledge of materials and construction methods, and an appreciation for professional practice." 21 These considerations should be given when incorporating BIM within academic curriculum.

The development and use of BIM within the construction industry is being heavily driven by the industry and practitioners and educators are having to not only attempt to keep up with the industry but also incorporate BIM within their curriculum simultaneously. ${ }^{2}$ Macdonald and Mills report that "faculty members do not always remain up-to-date with technical software applications used in industry." 22 They further suggest that this can be alleviated with "closer integration between industry and academia." 22 For these reasons, it seems to make sense that programs should be working more closely with industry to strengthen their BIM curriculum and ensure that student's abilities upon graduation meet industry needs and expectations. This was the motivating factor for the faculty visits with BIM contractors summarized within this paper.

The intention of this work was to better understand the industry needs and how BIM is being utilized in the "real world," and to use this information to make any warranted changes within our curriculum to meet those needs. The remainder of this paper focuses on the lessons that we learned from industry and in general what those mean for BIM related curricula. At the request 
of the companies, only general information will be provided herein, including the identity of the companies and projects visited. However, the information learned during these site visits has already strengthened the way that we teach BIM within our curriculum and allowed for our students to be learning BIM essentially the same way that it is practiced within the industry. The lessons learned from industry are broken into two separate categories: one related to the organizational structure of BIM data and the other to BIM personnel.

\section{Part 1 - BIM Data and Organizational Structure}

This section includes lessons learned about BIM processes used in industry. These are summarized within this paper to demonstrate that there is much to be learned from industry in helping strengthen our academic programs. These topics have been incorporated into the curriculum to provide students with a better understanding about best BIM processes used in industry.

\section{Utilization of BIM within the Construction Industry}

During the site visits it was observed that BIM was used to plan and sequence construction, make work plan documents for self-performed work, design coordination, construction coordination, communicate with neighbors to help understand the project's impact on them, estimating, and owner visualization of space. These appeared to be the predominant uses of BIM on the projects visited. Is every project right for BIM and is BIM essential on every project? These are questions that are often asked and everyone seems to have a different answer. From what was observed during the site visits, projects where the contractor was involved early in design seemed to benefit the most from the BIM process. That is not to say that BIM can't be used on projects using traditional design-bid-build, but they simply don't appear to receive as much benefit when BIM is not utilized through both design and construction. A lot of the benefit that BIM brings to the table is that the owner, contractor and design team have the ability to communicate more effectively when using BIM. This is one of the most important aspects of BIM that students should gain an appreciation for, and students should be taught how to effectively communicate with BIM.

\section{BIM Execution Plans}

BIM is a great tool for increasing communication, especially if there is a clear and concise plan in place. Without a plan, many of the benefits of using BIM are not as easily observed. A BIM execution plan is used to define the process for using BIM within the project. A BIM execution plan lets each party know what is expected of them throughout the project. The execution plan should not be full of a lot of generic text. Rather it should be a focused document, and it should include a company's "best practices" as a starting point for each project. It should clearly set the BIM expectations and set forth how all parties should be held to the expectations that are established. It is assumed that the BIM execution plan will then be followed. Although the BIM execution plan should be a document that is guided by one party, every party should have input into the document to ensure that the requirements and expectations are achievable. This is being used to help students understand the processes involved in utilizing BIM within a project A 
sample of a BIM execution plan can be found at:

http://cmfac.groups.et.byu.net/miller/BIM/EP/BIMExecutionPlan.pdf.

Another document that one company has implemented to help coordinate their drawings is what they call the "Golden Rules" document. The Golden Rules document is intended to be used as a guide for coordination to provide general parameters for the placement of various services in the BIM process. The document is intended to be an aid in the coordinating and also receives input from all the parties involved before it is added to the guidelines. This too is being shared with students to help them understand the process for establishing services within the BIM process. A sample of the Golden Rules document can be found at: http://cmfac.groups.et.byu.net/miller/BIM/EP/GoldenRulesExample.pdf.

\section{The Organization of BIM Departments within Companies}

Based on the observations, BIM seems to work best when it is highly integrated within Precon and Operations rather than as a separate department, unless it is a very small core group of individuals. This core group can help direct the technical direction of the rest of the company and also provide the training to the BIM project engineers and the BIM assistant superintendents. A similar parallel exists in regards to how safety is commonly handled within a company. Typically there is a small safety department with onsite personnel responsible for safety on the job site, with the central safety director being a resource for the site personnel.

\section{BIM use in the Field}

For companies that self-perform work, creating work-plan documents using BIM can be very beneficial. A work-plan document contains all the information needed for crews to perform the work for a particular task. For example, a foundation crew work-plan document would contain the necessary plan and section views, as well as all the needed dimensions and order quantities. This allows the crew to need only one drawing sheet for the work to be performed. This saves searching all over the plans and potentially having to scale the drawings.

One of the more innovative ways that BIM was being utilized in the field was through an onsite toolbox computer. The toolbox computer is a weatherproof box (see figure 1) containing a central computer that project personnel can use to access project related documents, including current drawings, models, RFI's, change orders, clash reports, specs, etc. The computer is connected wirelessly to the project office and the

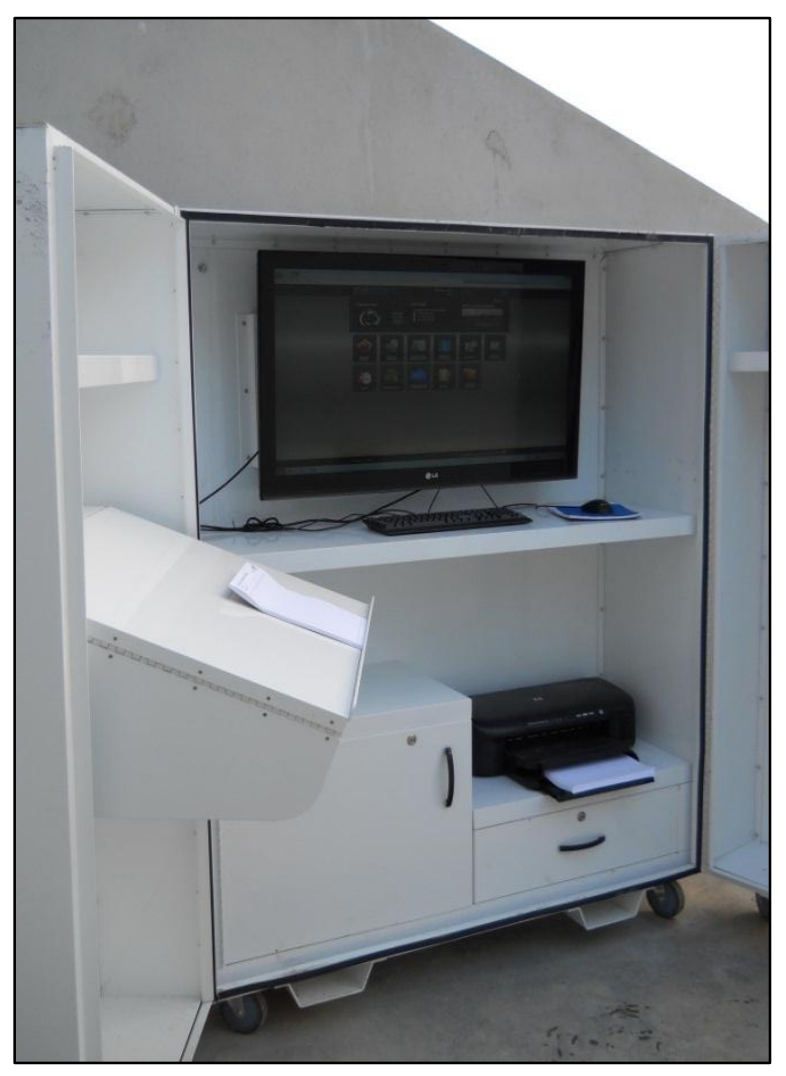

Figure 1: Toolbox computer. (Photo courtesy of Mortenson Construction) 
internet. Each user is required to log in, which allows for different levels of access to the project documentation. Some companies have made custom work-plan documents where all the drawings, details, quantities etc. are all placed on a single sheet, so that any crew can quickly and more efficiently look at only their segment of work. This is typically done by companies that have self-performing work. A toolbox computer (or BIM box, as called by some) on the jobsite was found to be extremely beneficial to the field employees for both the general contractor and the trade contractors. While walking around a project site, a foreman gave an unsolicited comment about how beneficial it was to have the computer onsite. It was also fascinating to observe general field workers using the toolbox computer setup as part of their normal course of work. Many of the companies visited were using this approach to providing the documents on their projects with the same observed results. It was observed that the toolbox computer was typically found on projects over 15 million dollars.

The recent innovation of portable electronic devices, such as the iPad or similar tablet computer, has allowed for BIM to be further integrated in the field. One of the companies visited was using a more current version of a Windows tablet computer in the field. The Windows tablet computers (slates) bridge the gap between the iPad and droid tablets and laptop computers, because they have full functionality available to them rather than having the typical viewing limitations that are available with tablets. Windows based programs generally have a broader and more complete feature set than those utilizing "apps." It was observed that the Windows tablets were available to most everyone in the company, but mainly utilized by PMs and Project/Field Engineers. This particular company would like to enable use for superintendents and general foreman, but is finding it challenging to overcome technological barriers. A few key differences were observed supporting the use of slates over iPads: first, slates utilize a Windows operating system, which was more familiar to project personnel and was more compatible with networking and server software; second, slates tend to have more computer power; and finally, slates can perform all the functions of a normal computer, but in tablet form.

\section{Data Structure}

The design models were often organized by the construction team into various work breakdown structures, i.e. areas, floor, etc., to be sequenced for construction. If the design and construction teams were in an arrangement other than design-bid-build, the design team was often open to adding a construction parameter or two in the model, thus greatly assisting the construction team in this effort.

\section{Flow of Data both Internally and Externally to the Company}

It was observed that there needs to be better alignment between the estimating, scheduling, project management and BIM processes. It is often spoken of how an integrated project delivery (IPD) method can break down the barriers between the owner, design team, contractor and subs. There needs to be a similar arrangement within a company, as it was observed that there can be just as many barriers in the form of information silos within a company as barriers between companies. There needs to be a complete overhaul in the process of how the data is structured internally, so that the same data isn't recreated for the estimating, scheduling and project management silos. 


\section{Part 2 - BIM Personnel}

\section{Realization that People are the Real Assets and BIM is Just a Technology Tool}

One of the companies visited emphasized that BIM is merely a technology tool, while people are the real assets and provide the competitive edge. With this in mind, this particular company actively promotes BIM training in many venues outside of the company, often providing tricks and tips on BIM to their competitors. This attitude helps promote BIM throughout the industry. Furthermore, certain skills can be readily taught and others cannot. The following email (with a few minor edits) sent by a company representative, captures this thought: (name withheld for confidentiality purposes)

"Studying various companies in various industries and through firsthand experience in construction, it has become quite apparent that processes, tips and tricks do not add up to a competitive advantage. While [there] may be... perceived advantage in a "first to market" sense, they are not long term strategies to maintaining a competitive advantage. Processes are easily duplicated and easily obtained by "purchasing" them. "Purchasing" can happen in various ways such as educational seminars, second tier subcontractors... or other educational methods such as the internet and social networking. They are easily obtained with often very little required expense. Processes can be easily taught and easily improved. However, people are the real competitive advantage.

Managing a project (people) effectively and understanding how to use the software tools to solve problems creatively, before they become problems, is really where a company can maintain a competitive advantage. The reason for my philosophy is that the skillset required to be an effective manager and use the software tools creatively to solve real problems is not easily obtained. It requires experience in construction, people skills, managerial skills, leadership skills, technology skills, innovation skills and the desire to take calculated risks, often referred to as intangible assets. While many of these skills can be taught, most require time, experience and the right personality. The intangible assets are the real long term strategic competitive advantage for any company. I can teach all of my processes to... students quite effectively and I would suppose that each of them would be able to duplicate what I have taught. However, the competitive advantage... is an employee who possesses the necessary people, managerial, leadership and innovation to solve a problem using the software tools.

The answer as to why I so readily share my tips and tricks is that I know that by doing so I will likely have a resource for innovation in the future. People with whom I share will more likely provide answers and solutions to issues that I might face in the future. I realize that I do not nor cannot know everything, and by sharing I have a network of individuals that might provide a spark that will lead to my solution. I give up a perceived "first to market" advantage to obtain long term strategic advantage."

It was interesting to hear the perspective from an industry professional, essentially saying that the focus of curriculum needs to be on developing managers and leaders and not just BIM 
technicians. This is not to say that BIM skills are not important, but that creativity, leadership, managerial, innovation, inquisitiveness, and problem solving skills are those abilities most sought after. When the two skillsets are coupled together, then the employee becomes an asset to the company. With the understanding that the creative people in the organization are the assets, sharing BIM processes with others becomes less threating and elevates the industry. When the lead author visited companies two years ago, some companies requested that a non-disclosure form be signed prior to the visit. The irony of that experience was that the companies that wanted the non-disclosure agreements felt they were leading the industry in BIM. However, it was apparent after the visits they were behind their competitors in implementing BIM.

As an academic program, industry sharing with us has greatly enhanced our classes, which in turn has greatly enhanced the students graduating from our program. We have also shared with the students the idea that "industry sharing" with academic institutions strengthens our program and likewise better prepares their future employees. After our students graduate we anticipate that they will be comfortable in sharing new ideas or trends with us because they benefitted from their predecessors sharing with them.

\section{Acknowledgment that BIM Specific Personnel Currently Have a Limited Career Path}

These visits also revealed that BIM provides a limited career path to those students who wish to rise to the executive level. Students would be better served by either pursuing a position as a project engineer or one in preconstruction, with an emphasis in BIM. Students interested in BIM also seeking to move up to the executive levels in a company should look for job titles like "BIM project engineer," "BIM assistant superintendent," or "BIM Estimator," which may be better for a more flexible long-term career path with less ceilings within in the company.

\section{Traditional CM Roles are Greatly Enhanced by a Strong BIM Skillset}

It was observed that many companies utilized their BIM departments to assist in performing quantity takeoffs. However, companies would be able to work more effectively if the preconstruction department would develop the necessary BIM skills to do the takeoffs. Unfortunately, the BIM departments for the companies visited did not have enough resources and in some cases enough background to know what quantities the preconstruction department needed. At several locations it was noted that the BIM staff came from an architectural background, thus having a strong modeling background, but lacking the construction background necessary to analyze the model from a preconstruction standpoint. Preparing all construction management students with BIM skills, to fulfill a variety of different roles within the construction company, will enhance a company's ability to utilize BIM at all levels.

Interestingly, it was observed that those with a strong architectural background and somewhat weaker preconstruction background felt somewhat unqualified to do anything other than BIM. It was suggested that these individuals should be given experiences/work assignments to help them feel more comfortable in areas such as preconstruction and operations. Companies should establish cross training to create skilled BIM personnel. This process could also be reversed to strengthen preconstruction personnel with BIM. 


\section{BIM Estimating Tools}

There are a variety of tools and methods available for contractors using BIM to perform quantity takeoffs with the models. However, it was observed that there was not a complete viable estimating solution. The following software packages were observed during the site visits.

Autodesk's Revit is good for performing quantity takeoffs of limited scope. Typically though, it involves modifying the model or filtering out data or objects that may not be relevant to the takeoffs that are going to be performed prior to performing the actual takeoff. Using Revit also allows the contractors to add additional data into the model. This is helpful when not all the information has been included by the design team. To help identify what has been "taken off," several people were using the "visibility graphic" properties and changing the color of the objects taken off. One of the shortcomings of using Revit as a takeoff tool, is that if the model doesn't include the objects that should be included in the takeoff, the missing objects will then need to be modeled and then taken off. This may exceed the skill set of the person doing the takeoff.

Autodesk's QTO has more capability for complete quantity takeoff, but the software is "buggy" and requires massaging the model prior to importing the data to QTO, like they do for takeoff in Revit. QTO's process provided the most complete path for the takeoff process. However, before the model goes to QTO it should be prepped in Revit. Timberline's QTO plugin allows for the estimating database to be opened inside of QTO, removing the feeling of a middleware product. QTO also allows for takeoff of objects that are not included in the model, as long as you have the $3 \mathrm{D}$ model and 2D sheets.

One firm was observed to be using Innovaya in their mainstream operations, although it seemed that many of the firms had tried/tinkered with it. Innovaya was a product used between the model and the estimating software. It had a lot of options that allow the user to view the model in a variety of ways, but it seemed that the user often needed to make changes in either the model or the estimating software. This created the feeling of middleware and frustration where the user couldn't make changes in the model or the estimate, the user could only map between these software packages.

\section{Changes Resulting From the Visits}

Prior to the visits, the author had a general understanding of what clash detection was supposed to do and used and academic approach to teaching clash detection. After seeing each company's different processes for clash detection the following changes were made to how clash detection was taught. The models were broken down into a floor by floor arrangement or a particular area of a floor so the process didn't seem so overwhelming, also making the process more efficient and consistent. Also, when the general contractor (GC) was leading the coordination effort, it worked better when the GC identified the clashes but let the subcontractor or design team recommend the solution to the clash. This process has been incorporated into the classroom lecture. It was discovered that without a well thought out BIM Execution Plan, efficient and effective clash detection is harder, if not impossible, to accomplish. The reason for this is that the BIM Execution plan defines what is to be modeled. If the BIM Execution plan is part of the 
contract documents, it is then binding on all project parties and becomes legally enforceable. This has also been incorporated into the lectures on BIM.

The visits to the various companies provided exposure to different methods of extracting quantities from models. Whether using different software packages to extract the quantities or using different processes inside of a single software package, the approaches to performing quantity takeoffs were analyzed to create a richer educational experience for the students providing them most current industry practices for quantity takeoffs. These approaches have been captured in various tutorials that the students are now able to use throughout various courses in the CM curriculum.

It was observed that the career path of a BIM Managers is limited in its upward mobility inside a company because there is not a defined BIM career path to the executive level. Since visiting the companies, our counseling to current students desiring executive level career paths has changed to advise students interested in a career path utilizing BIM, to seek traditional roles within a company allowing them to maintain a BIM emphasis.

Prior to these company visits, our program had already made the decision to treat BIM as a tool used in construction, rather than providing a BIM specialization or having several BIM specific courses. These visits confirmed that this decision is the approach that we want to continue to pursue. The program currently has a single course (Construction Modeling) completely dedicated to BIM, with an additional three courses (Introduction to Construction Management, Construction Sustainability, and Preconstruction Services) having BIM components within the course. During this next year, additional courses (Concrete, Project Management, and Safety) are also adding BIM components. Other courses are also being reviewed and considered for integration of BIM components into the curriculum.

An unexpected result from these visits was the general perception of the students about the BIM related courses taught by the primary author. A course incorporating BIM prior to the visit had an overall course rating 6.5 out of 8 . The semester after the visits and implementation of the industry related experience into the course, the course rating jumped to 7.4 on an 8 point scale. Two of the specific student comments after the visits were:

- "He always took time to help his students and to improve his course."

- "He tries the hardest to stay with the times and makes sure he is teaching us what is in the industry right now. I am very grateful for that."

While receiving better student evaluations were not necessarily the object of the visits, the students did appreciate the course materials being current. It should also be noted that industry representatives have been very supportive of the office visits knowing that what they were sharing was being utilized to strengthen the student's abilities in learning BIM and preparing for their careers as construction managers. 


\section{References}

[1] McGraw-Hill Construction. Building Information Modeling: Transforming Design and Construction to Achieve Greater Industry Productivity, McGraw-Hill Construction, New York, 2008.

[2] Arnett, K.P. and Quadrato, C.E., AC 2012-4356: Building Information Modeling: Design Instruction by Integration into an Undergraduate Curriculum. Annual Conference Proceedings, American Society for Engineering Education, 2012.

[3] Kim, J.L., 2012. Use of BIM for Effective Visualization Teaching Approach in Construction Education. Journal of Professional Issues in Engineering Education and Practice. Vol. 138, No. 3, pp. 214-223.

[4] Sharag-Eldin, A. and Nawari, N.O. BIM in AEC Education. Structures Congress Proceedings, American Society Civil Engineers, 2010.

[5] Meadati, P. and Irizarry, J. BIM - A New Teaching Tool. Proceedings of the ASEE Southeast Section Conference, American Society for Engineering Education, 2011.

[6] Gao, Z., McIntyre, C., and Ge, Z., AC 2012-4868: Integrating Building Information Modeling (BIM) in Teaching Project Scheduling and Control. Annual Conference Proceedings, American Society for Engineering Education, 2012.

[7] Hyatt, B.A., A Case Study in Integrating Lean, Green, BIM into an Undergraduate Construction Management Scheduling Course. Proceedings of the $47^{\text {th }}$ ASC Annual International Conference, Associated Schools of Construction, 2011.

[8] Gier, D.M., What Impact Does Using Building Information Modeling Have on Teaching Estimating to Construction Management Students? Proceedings of the $44^{\text {th }}$ ASC Annual International Conference, Associated Schools of Construction, 2008.

[9] Sylvester, K.E. and Dietrich, C., Evaluation of Building Information Modeling (BIM) Estimating Methods in Construction Education. Proceedings of the $46^{\text {th }}$ ASC Annual International Conference, Associated Schools of Construction, 2010.

[10] Liu, J. and Killingsworth, R., A Study of Using BIM as an Innovated Teaching Tool in an Estimating Class - A Preliminary Report. Proceedings of the $48^{\text {th }}$ ASC Annual International Conference, Associated Schools of Construction, 2012.

[11] Sacks, R. and Barak, R., 2010. Teaching Building Information Modeling as an Integral Part of Freshman Year Civil Engineering Education. ASCE Journal of Professional Issues in Engineering Education and Practice, American Society of Civil Engineers, Vol. 136, No. 1, pp. 30-38.

[12] Korman, T. and Simonian, L., AC 2010-23: Using Building Information Modeling to Teach Mechanical, Electrical, and Plumbing Coordination. Annual Conference Proceedings, American Society for Engineering Education, 2010.

[13] Peterson, F., Hartmann, T., Fruchter, R., and Fischer, M., Teaching Construction Project Management with BIM Support: Experience and Lessons Learned. Automation in Construction. Vol. 20(2). Elsevier Science B.V., Netherlands, 2010.

[14] Woo, J.H., Building Information Modeling and Pedagogical Challenges. Proceedings of the $43^{\text {rd }}$ ASC Annual International Conference, Associated Schools of Construction, 2007. 
[15] Dupuis, M., Thompson, B., Bank, L. and Herridge, J., AC 2008-2356: Experiences Implementing an Undergraduate Civil Engineering Course in BIM. Annual Conference Proceedings, American Society for Engineering Education, 2008.

[16] Cooksey, J.M. and Schiff, S.D. Integration of Building Information Modeling (BIM) into a Civil Engineering Curriculum. Proceedings of the ASEE Southeast Section Conference, American Society for Engineering Education, 2012.

[17] Becerik-Gerber, B., Gerber, D.J., and Ku, K., 2011. The Pace of Technological Innovation in Architectural, Engineering, and Construction Education: Integrating Recent Trends into the Curricula. Journal of Information Technology in Construction. Vol. 16, pp. 411-431.

[18] Lee, N. and Dossick, C.S., AC 2012-4816: Leveraging Building Information Modeling Technology in Construction Engineering and Management Education. Annual Conference Proceedings, American Society for Engineering Education, 2012.

[19] Nejat, A., Darwish, M.M., and Ghebrab, T., AC 2012-5582: BIM Teaching Strategy for Construction Engineering Students. Annual Conference Proceedings, American Society for Engineering Education, 2012.

[20] Barison, M.B. and Santos, E.T. The Competencies of BIM Specialists: a Comparative Analysis of the Literature Review and Job Ad Descriptions. Computing in Civil Engineering, American Society Civil Engineers, 2011.

[21] American Institute of Architects (AIA), 2006. Report on Integrated Practice. AIA.

[22] Macdonald, J.A. and Mills, J.E., AC 2011-1346: The Potential of BIM to Facilitate Collaborative AEC Education. Annual Conference Proceedings, American Society for Engineering Education, 2011. 